\title{
Suggestion on Engineer Education and Training in China
}

\author{
Hao Chen ${ }^{1, a}$, Yali Yang ${ }^{1, b}$, Yansong Wang ${ }^{1, c}$ \\ ${ }^{1}$ College of Automotive Engineering, Shanghai University of Engineering Science, Shanghai, \\ 201620, China \\ aemail:pschenhao@163.com, bemail:carolyn71@163.com, bemail:jzwbt@163.com
}

Keywords: Excellent engineer; Education and Training; Suggestion

\begin{abstract}
The Education and Training Program of Excellent Engineers (ETPEE) is the fundamental scheme for the college education quality system in the next ten years, to improve engineer education and training. This paper introduced the engineering education in foreign countries, discussed the current situation of engineering education in China. Based on the requirement of ETPEE and Chinese engineering education character, the suggestion on engineer education and training was presented, thus to improve the high quality and ability engineering talent development for economy and technology development in China.
\end{abstract}

\section{Introduction}

The Education and Training Program of Excellent Engineers (ETPEE) is an important reform project that is for the implementation of the Outline Program for National Medium and Long-term Education Reform and Development (2010-2020) and Outline Program for National Medium and Long-term Development for Talented Personnel (2010-2020), and is also an important measure to promote the transformation of China from a country with large scaled engineering education programs to the one with advantageous programs in engineering education and training. It aims to educate a large number of qualified engineering professionals who are highly innovative, and catering to the needs of socio-economic development, which plays a very important role in promoting China's drive to take a new industrialized style of development to rejuvenate the nation.

The Program boasts three outstanding features: firstly, it involves the deep participation of businesses and industries. Secondly, the engineering students are educated and trained according to general and industrial standards. Thirdly, great importance is attached to the development of students' engineering and creative capability[1].

The ETPEE program is the fundamental scheme for the college education quality system in the next ten years, which requires reform on traditional engineering talent cultivation mode. The objective of this paper is to explore the proper way to promote the program.

\section{Engineer education and training in USA and Germany}

Currently, there are two major kind of engineer education and training. One is the registered engineer mode in USA, the other one is the diploma engineer mode in Germany.

USA mode: USA mode is characterized as registered engineer mode, aiming to ensure the professional and moral level of engineers. This certified qualification is the compulsory requirement for engineers. Three stages are included. First, college education on engineering major is required, with bachelor degree or equivalent degree. Then, basic engineering test should be accomplished, which is organized by National Council of Examiners for Engineering and Surveying (NCEES). Those who pass the test can gain the title of trainee engineer, which can do engineering work under the supervise of professional engineer. Trainee engineer who practice for four years and past the professional engineering test of NCEES can get the title of formal professional engineer.

Germany mode: Engineer education in Germany is characterized as the diploma engineer mode. In the mode, the professional education is collected with qualification system. A qualified engineer is required to accomplish all the training and education for a professional engineer. Engineer education system is the combination of education and practice training. During the whole process, 
student is required to pass the fundamental and professional study. The engineer title will be gained after the student pass the intership stage[2].

\section{Status of engineering education in China}

Engineer education and training is far more behind the rapid economical and social development, which severely affect the development in China .

\section{Education emphasizing on lectures}

Education and training on engineer is lecture emphasized, which is characterized in dominated speaking and teaching by teachers. Students were passive receiver, not active participants in class, resulting in lower learning initiative, less thinking and feedback. Classroom teaching is made up of teaching and learning. It is a bilateral activity that teachers and students must join in together.

All the teaching arrangement, like syllabus, teaching plan, teaching methods, is settled under the foundation that teacher is always the main body, and student is the object body. Student is treated as passive receiver, which reduces the learning initiative and innovation consciousness.

Low engineering ability of teachers

Many teachers are lack of practical engineering experience, especially the young teachers, which significantly constrain the engineering ability. Due to the evaluation system in college education, many teachers are forced to shift their emphasis on theory rather than practice. Furthermore, few college has thoroughly collaboration with companies. Really practice and requirement is less considered in college teaching, which results in aimless teaching, outmoded teaching content, rigid teaching methods, thus cause inconsistence between theory and practice[3].

Insufficient and inefficient practical teaching

First, insufficient practice infrastructure results in shortage of practice base. Some colleges even do not have in-school base and stable outside base. Second, practice teaching method is few. The main method is one-way lecture on theory, which weak the operational ability and creativity of student. Third, weak management on practice teaching reduces teaching results. No systematic management on practice teaching was found in most colleges. Practice teaching is more related on student self-contact outside company without proper supervision and management. The existing practice bases are not well managed, with lower efficiency[4].

Unclear learning initiative for students

Although the population of student in engineering area is quite big, many students do not have clear initiative on study. They are not familiar with the engineering needs and content in their majors. Under the examination-oriented education system, student puts more effort on the test, rather than ability improvement. To get the degree, student put more emphasis on easy and theoretical course. Few student put themselves in engineering practice.

\section{Suggestion on excellent engineer education and training}

Optimize course system and teaching content

Current course system is the continue of traditional teaching mode, which emphasize on theoretical knowledge learning, and ignore real engineering and multi-discipline application. Low correlation is founded between current practice teaching content with real engineering application. Therefore, student is only restricted on theoretical learning. Less opportunity is provided for student to use knowledge to analyze and solve real engineering problems. The lack of training on design and comprehensive ability to solve real engineering issue significantly constrain the innovation consciousness and operational ability.

The main feature for modern technology development is integrated innovation. Multi-discipline knowledge and skill are essential to solve a real engineering issue. Therefore, course system and content should shift from traditional lecture learning mode to real engineering based teaching. Real engineering cases, projects, and problems should be highly emphasized. Explore of correlation between theory and practical engineering should be also strengthened. The course teaching should be updated with real engineering, and multi-discipline innovation should also be enhanced[5]. 


\section{Student-oriented teaching mode and methods}

The aim of ETPEE is to cultivate the ability in practice, engineering design and innovation of students. Therefore, the teaching mode should be oriented on student ability.

Along with the rapid development in technology, more knowledge should be included in course teaching, which requires course teaching making the shift from one-way lecture to multi-methods teaching. Inspiration, steering, interaction and comparison should be combined into teaching arrangement, to increase the participation of students. Modern teaching methods, such as situational teaching, problem based research teaching, CDIO mode teaching, engineering project based case study, should be taking into consideration.

Situational teaching. Course teaching should be taken place in the similar circumstance as real situation, like moving teaching to lab, thus to solve the problems which students encounter and improve the ability on problem solution, by using real or semi-real engineering environment. Modern multi-media technology should be also include, to increase the vitality and visualization.

Engineering case study. For some professional and practice oriented courses, engineering case study should be emphasized. Case method is a very important method to improve the interest of students, and integrate theory and practice, thus to improve the ability of utilizing knowledge to solve actual problem. Therefore, course teaching should include theoretical teaching and real engineering case study. Multi-discipline knowledge can be used in case study to solve real engineering issues, to improve students' real engineering ability[5].

Problem based research study. Student actively participate in the problem solution, under the instruction of teacher. Teacher needs to present the problem with background information, encourage student to accomplish the task. The main task should be done by student. Through this initiative process, student shifts their knowledge gain mode from passive to active, thus to widen the innovation space and engineering ability.

\section{Improve assessment system}

Current assessment system is knowledge point oriented, with more emphasis on test score, rather than learning process and actual learning results. Students are forced to put more effort on test score, few is put on practice and ability improvement. Therefore, the assessment system should be improved based on the requirement of ETPEE program. The concept should be changed from test score focusing to learning process orientation. Only this, can guide student into active studying, and improving ability in multi-discipline knowledge application and real engineering issue solution.

\section{Improve training practice in real industry environment}

For the ETPEE program, a large proportion is engineering training in real industry environment, which probes into the real company operation, product design and manufacture activities.

Firstly, industry training bases establishment should be enhanced. Policy support from government should be placed to encourage companies to go deep into the collaboration with universities. Certain amount of national center should be established. University should take advantage of talent base, strengthen relationship with companies by provide high quality and ability graduates. The teaching should be connected with industry needs, and make proper adjustment based on local economy development and company need.

Secondly, industry training should be proper managed. Management system should be established for ETPEE program, which is in charge of collaboration of company and university, thus to form the platform of industry-university-research cooperation. Supervisor from university and company should be assigned for engineer training. Both supervisors should have real engineering experience, and with high professional skill and responsibility.

Thirdly, industry training content should be prospered designed. Industry training content should be designed based on training purpose and company real engineering condition. Four contents should be included, company acknowledgement, operation skill training, engineer skill training, and real engineer issue solving. Company acknowledgement consists of company business process, product, equipment, culture and so on. Operation skill training is mainly the practical operation skill training, such as product manufacture methods and technology training. Engineer skill training includes industry standard, criteria training, to develop the engineering job qualification skill in 
system design, development and management. Real engineer issue solving could be placed on the senior project. It can be done by combining industry training or participate in the real industry product design and development project[6].

Improve teacher's engineering ability

Teachers' engineering ability is critical for the program. University should encourage teacher to do real engineering work with companies, to understand the operation mode and working process of companies. It can be done through spare time working, taking a temporary position in company, and research collaboration with company. Senior engineer and talent with plenty of engineering experience should be introduced to university as teachers, to direct engineering teaching.

Enhance international education and training

Along with the global development, talent with international view and collaboration ability is required for modern engineering development. Foreign professors can be included in engineer education and training. Their teaching and research interest can widen student horizon, and their teaching methods puts more emphasis on two way communication teaching method, that is, heuristic education method. Heuristic education emphasizes not only on information transfer, but also ability development of learning and communication. Students are thoughts as active participants in teaching and learning. The using of this method can obviously improve the ability of students on problem solving, thus to enhance learning initiative and effect ${ }^{[6]}$. Student can take the advantage of international cooperation with foreign countries. They can go abroad for short term training, exchange, senior project, and long term education. Through the engineer education and training abroad, student can not only understand the engineering world outside, but also have their engineering ability improved with international concept[7].

\section{Conclusion}

The ETPEE program is the fundamental scheme for the college education quality system in the next ten years, which is foundation of shifting for the outstanding education in China. Profound reform should be taken place in engineer education and training. More research should be done deep in the system establishment and improvement, thus to provide abundant high quality and ability engineering talent for economy and technology development.

\section{Acknowledgement}

This work is sponsored by the 12nd Five-year Support Program in Shanghai University of Engineering Science (2012-09-nhky).

\section{References}

[1] Lin Jian. On the professional training program of "A plan for educating and training outstanding engineers”. Tsinghua Journal of Education, 2011,32(2):47-55.

[2] Lou Ping, Zhang Xiaomei and Jiang Xuemei. Inspiration for engineer education from USA and Germany. Talent Education, 2012,226:57-58.

[3] Yu Manman. Excellent engineer educaiton with government-industry-university cooperation. Chinese University Technology Transfer, 2001, 4: 64-65.

[4] Zhou Xuemei, Teng Jing. Teaching reform on the basis of excellent engineer education and training. China Education Innovation Herald, 2011, 5:50.

[5] Robinson, Marc."How to write a case study," William Davidson Institute note 1-429-140, Rev. October 10, 2010

[6] Song Peiwei. Innovation ability improvement for excellent engineer. Talent Education. 2011,7:25-27.

[7] Zhang Lihua, Wang Qi, Fang Xifeng et al. Teaching Reform and Practice of Professional Production-practice based on “Outstanding Engineers”. Academic Research, 2011,1:16-19. 